\title{
INDEKS KEANEKARAGAMAN ECHINODERMATA DI PANTAI TANJUNG SETIA KABUPATEN PESISIR BARAT SEBAGAI SUMBER BELAJAR BIOLOGI SMA KELAS X
}

\author{
Dini Arifah ${ }^{1}$ \\ Handoko Santoso ${ }^{2}$ \\ Rasuane Noor ${ }^{3}$
}

\author{
1,23) Pendi dikan Biol ogi, FKIP, Uni versitas Muhammadi yah Metro \\ E-mail: arifahdini77@g mail.com, handoko.umm@g mail.com, rasuanenoor@gmail.com
}

\begin{abstract}
Echinoderms are an invertebrate animal consisting of 5 classes, all of its members live in the sea. Echinoderm inhabits the shallow sea to a certain depth. Tanjung Setia beach is a beach with coral substrate and seagrass which is echinoderms habitat. Based on visits ever made, it is known that this beach has many echinoderms. The number of species of this coastal echinoderms is unknown as does its diversity index. The purpose of this research is to know the species of Tanjung Setia echinoderms, along with its diversity index. This research is descriptive research, the technique used random sampling by using the combination of line transect and quadrant. Based on research that has been done that there are 12 species of echinoderms, with H' medium.
\end{abstract}

Kata kunci: indeks keanekaragaman, echinodermata, Pantai Tanjung Setia

Echinodermata merupakan hewan tak bertulang belakang. Hewan ini sering disebut dengan hewan berkulit duri. Anggota filum echinodermata terdiri atas 5 kelas yaitu Asteroidea, Ophiuroidea, Echinoidea, Holonthuroidea dan Cnidaria. Echinodermata seluruh anggotanya hidup dilaut (Romimohtarto \& Juwana, 2007). Habitat echinodermata berupa laut dangkal dengan substrat karang, pasir, dan padang lamun.

Kelompok

hewan echinodermata merupakan salah satu komponen penting dalam keragaman fauna di daerah terumbu karang. Kelompok hewan ini dikenal sebagai hewan pembersih pantai. Disebut demikian karena echinodermata secara ekologis berperan sebagai detritus perairan. Contoh fauna echinodermata yang berperan sebagai detritus yaitu bintang laut, bintang ular dan bulu babi. (Yusron dalam Pallo \& Lewaherilla, 2011).
Pantai Tanjung Setia merupakan pantai yang terletak di desa Tanjung Setia, Kecamatan Pesisir Selatan, Kabupaten Pesisir Barat, Lampung. Pantai ini menghadap langsung pada samudera Hindia, serta tidak ada pulau yang berada di tengah-tengah pantai ini. Pantai Tanjung Setia dikenal sebagai destinasi wisata selancar karena ombaknya yang besar dan indah. Belum banyak orang yang mengetahui sisi edukatif dari pantai Tanjung Setia, misalnya dapat dijadikan sebagai tujuan praktikum lapangan baik untuk perguruan tinggi maupun sekolah-sekolah.

Pantai Tanjung Setia sendiri memiliki banyak biota laut, salah satunya yaitu filum echinodermata. Anggota filum ini mudah ditemukan karena airnya yang jernih dan subrat yang mendukung seperti makroalga, lamun, karang dan subtrat pasir halus sebagai habitat echinodermata. Padang lamun merupakan salah satu ekosistem yang sangat penting, baik 
secara fisik maupun biologis. Selain sebagai stabilisator sedimen dan penahan endapan, padang lamun berperan sebagai produsen utama daring jarin-jaring makanan. Padang lamun juga menjadi tempat naungan, mencari makan dan berkembang biak berbagai jenis biota, baik invertebrata maupun vertebrata Kusnadi (dalam Apriliani dkk, 2014). Echinodermata yang ada di Pantai tanjung Setia ini belum diketahui spesies serta indeks keanekaragamannya, karena belum pernah ada yang melakukan penelitian di pantai ini. Indeks keanekaragaman merupakan sesuatu yang dapat digunakan untuk menyatakan hubungan kelimpahan suatu spesies dalam suatu komunitas (Sianipar dkk, 2015).

Tujuan dalam penelitian ini yaitu untuk mengetahui apa saja spesies echinodermata yang ada di Pantai tanjung Setia, serta mengetahui nilai indeks keanekaragaman dari echinodermata yang telah ditemukan di Pantai Tanjung Setia untuk mengetahui tingkat keanekargaman echinodermata di pantai ini berada pada kategori tinggi, sedang atau rendah. Hasil temuan echinodermata akan dijadikan sebuah sumber belajar berupa ensiklopedia.

Ensiklopedia merupakan merupakan salah satu jenis dari buku pengayaan yang dapat digunakan sebagai sumber belajar. Materi dalam ensiklopedia disajikan secara sistematis, beberapa ada yang mengurutkannya berdasarkan abjad. Salah satu kelebihan ensiklopedia ini dapat merangsang siswa untuk berpikir kritis, aktif dan kreatif. Ensiklopedia juga dapat digunakan untuk meningkatkan pengetahuan kognitif secara umum pada siswwa.
Keuntungan lain yaitu siswa dapat memperoleh informasi yang detail mengenai bahasan yang disajikan. Ensiklopedia juga ddapat dijadikan untuk melengkapi buku teks dan dapat dijadikan sebagai penyedia informasi baru dalam pembelajaran (Devy, 2015).

\section{METODE}

Penelitian ini menggunakan metode deskriptif dengan pendekatan kualitatif. Arikunto (2010) menyatakan bahwa penelitian deskriptif adalah penelitian yang tujuannya yaitu untuk memaparkan dan menggambarkan kejadian yang dapat dilihat dari data hasil penelitian. Kehadiran peneliti dalam penelitian yaitu sebagai instrumen sekaligus pengumpul data.

Pengambilan data dilakukan secara langsung di pantai Tanjung Setia, menggunakan teknik random sampling dengan menggunakan kombinasi line transek dan metode kuadran pada masing-masing stasiun. Dalam penelitian menggunakan 3 stasiun dengan harapan dapat menggambarkan suatu keadaan dan kondisi perairan pantai Tanjung Setia tersebut. Tiap-tiap stasiun dibentangkan transek sepanjang 100 meter.

Penelitian ini dilakukan di pantai Tanjung Setia Kabupaten pesisir Barat, yang terletak di Desa Tanjung Setia, Kecamatan Pesisir Selatan, Kabupaten Pesisir Barat Lampung. Penelitian ini dilakukan pada bulan Maret 2017. Pengambilan sampel dilakukan pada pagi hari saat laut surut. Pengukuran parameter kualitas air dilakukan satu kali. Parameter air yang diukur yaitu parameter fisika dan kimia.

Sumber data dibagi menjadi dua yaitu data primer dan sekunder. 
Data primer berupa semua temuan echinodermata di Pantai tanjung Setia, dan data sekunder merupakan pengukuran kualitas air. Teknik analisis data yang digunakan dalam penelitian ini dengan menggunakan rumus Indeks keanekaragaman Shanoon-Winner dan indeks dominansi.

Indeks keanekaragaman digunakan untuk mengetahui tingkat keanekaragaman echinodermata di Pantai Tanjung Setia, dan indeks dominansi digunakan untuk mengetahui spesies echinodermata yang mendominasi Pantai Tanjung Setia.

Menurut Shannon and Wienner (dalam Rappe, 2010):

Dengan,

$$
\mathrm{H}^{\prime}=-\sum\left(\frac{n i}{N} \ln \frac{n i}{N}\right)
$$

$$
\begin{aligned}
& H^{\prime}=\text { indeks keanekaragaman } \\
& \text { Shannon-Wienner } \\
& \mathrm{Ni}=\text { jumlah individu dari suatu jenis } \\
& \mathrm{i} \\
& \mathrm{N}=\underset{\text { jumlah total individu seluruh }}{\text { jenis }}
\end{aligned}
$$

Besarnya indeks keanekaragaman jenis menurut Shannon Wienner didefinisikan sebagai berikut:

a. Nilai $H^{\prime}>3$ menunjukan bahwa keanekaragaman echinodermata pada suatu transek adalah melimpah tinggi.

b. Nilai $H^{\prime} 1 \leq H^{\prime} \leq 3$ menunjukan bahwa keanekaragaman echinodermata pada transek adalah sedang melimpah.

c. Nilai $H^{\prime}<1$ menunjukan bahwa keanekaragaman echinodermata pada suatu transek adalah sedikit atau rendah.

Untuk perhitungan indekks dominansi digunakan rumus berikut:

$$
\text { ID }=\sum(\mathbf{n . i} / \mathbf{N})^{2}
$$

Keterangan:

$\mathrm{ID}=$ indeks dominansi

$\mathrm{n} . \mathrm{i}=$ nilai penting tiap spesies ke- $\mathrm{i}$

$\mathrm{N}=$ total nilai penting

Tabel 1. Kategori Indeks Dominansi

\begin{tabular}{|c|c|}
\hline Dominansi & Kategori \\
\hline $0,00<\mathrm{C} \leq 0,50$ & Rendah \\
\hline $0,50<\mathrm{C} \leq 0,75$ & Sedang \\
\hline $0,75<\mathrm{C} \leq 1,00$ & Tinggi \\
\hline
\end{tabular}

Sumber: Rappe ( 2010)

Alat yang digunakan dalam penelitian ini yaitu termometer, DO meter, refraktometer, $\mathrm{pH}$ meter, tali rafia, meteran, alat tulis, buku catatan, kamera, ember, nampan dan penjepit makanan. Sedangkan bahan yang digunakan yaitu semua temuan echinodermata dan sampel air untuk mengetahui parameter kualitas air di Pantai Tanjung Setia. Pengecekan kebasahan data menggunakan jurnaljurnal echinodermata yang relevan. 


\section{HASIL}

1. Parameter kualitas Air Pantai Tanjung Setia

Tabel2. Hasil pengukuran parameter kualitas air

\begin{tabular}{|c|c|c|c|c|}
\hline Stasiun & $\begin{array}{c}\text { Tempe ratur } \\
(\text { suhu) }\end{array}$ & $\begin{array}{c}\text { De rajat } \\
\text { keasaman } \\
(\mathbf{p H})\end{array}$ & $\begin{array}{c}\text { Kadar } \\
\text { garam } \\
\text { (salinitas) }\end{array}$ & $\begin{array}{c}\text { Oksigen terlalut } \\
\text { (DO) }\end{array}$ \\
\hline Stasiun 1 & $28^{\circ} \mathrm{C}$ & 7,6 & 22,6 & 19 \\
\hline Stasiun 2 & $28^{\circ} \mathrm{C}$ & 7,5 & 22,6 & 21,9 \\
\hline Stasiun 3 & $27^{\circ} \mathrm{C}$ & 7,3 & 24 & 22,56 \\
\hline
\end{tabular}

\section{Keanekaragaman Echinodermata}

a. Indeks Keanekaragaman Echinodermata

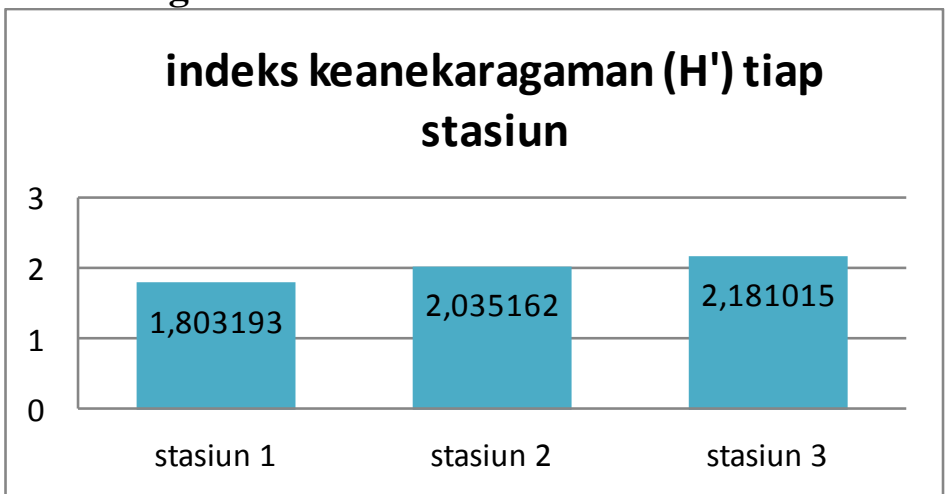

Gambar 1. Diagram Indeks Keanekaragaman (H') Tiap-tiap Stasiun

Dari ketiga stasiun, stasiun yang memiliki indeks keanekaragaman $\left(\mathrm{H}^{\prime}\right)$ tertinggi adalah stasiun 3, sedangkan yang terendah adalah stasiun 1 .

b. Indeks Dominansi Echinodermata

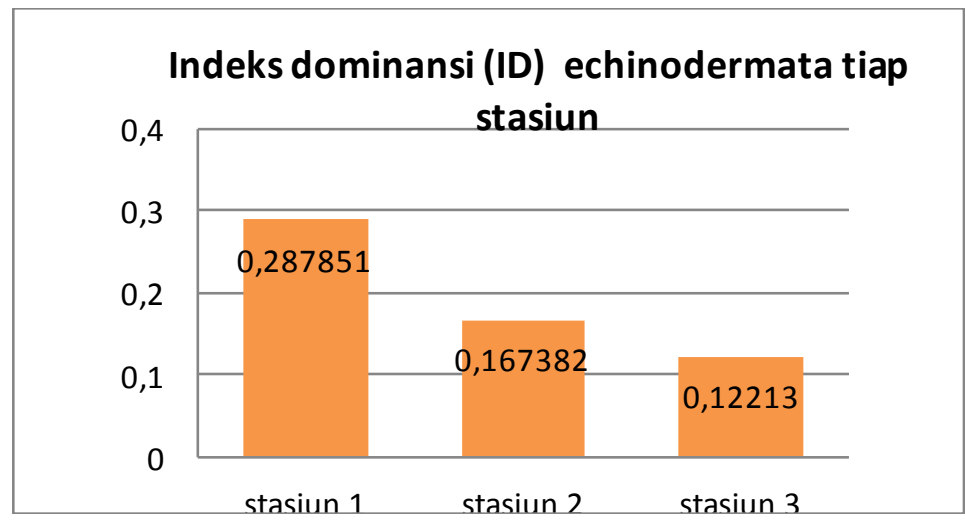

Gambar 2. Indeks Dominansi (ID) Tiap-tiap Stasiun

Dari diagram diatas dapat diketahui bahawa indeks dominansi tertinggi terdapat pada stasiun 1 , sedangkan yang terendah yaitu berada pada stasiun 2. 
3. Hasil Validasi Ensiklopedia

Tabel 8. Tabulasi Data Hasil Validasi Panduan Praktikum

\begin{tabular}{|c|c|c|c|c|c|c|}
\hline \multirow[b]{2}{*}{ No } & \multicolumn{2}{|c|}{ Indikator Penilaian } & \multicolumn{2}{|c|}{ Skor (\%) } & \multirow[b]{2}{*}{$\begin{array}{l}\text { Rata- } \\
\text { rata }\end{array}$} & \multirow[b]{2}{*}{ Krite ria } \\
\hline & Ahli Materi & Ahli Desain & $\begin{array}{l}\text { Ahli } \\
\text { Mate } \\
\text { ri }\end{array}$ & $\begin{array}{l}\text { Ahli } \\
\text { Desain }\end{array}$ & & \\
\hline 1 & $\begin{array}{l}\text { Keluasan } \\
\text { materi } \\
\text { ensiklopedia }\end{array}$ & $\begin{array}{l}\text { Tata letak judul, } \\
\text { gambar, nama } \\
\text { pengarang }\end{array}$ & 100 & 80 & 90 & $\begin{array}{l}\text { Sangat } \\
\text { Valid }\end{array}$ \\
\hline 2 & $\begin{array}{l}\text { Keakuratan } \\
\text { fakta dan } \\
\text { konsep }\end{array}$ & $\begin{array}{l}\text { Perpaduan } \\
\text { warna dan } \\
\text { tulisan pada } \\
\text { sampul } \\
\text { harmonis }\end{array}$ & 100 & 80 & 90 & $\begin{array}{c}\text { Sangat } \\
\text { Valid }\end{array}$ \\
\hline 3 & $\begin{array}{l}\text { Kesesuaian } \\
\text { penulisan } \\
\text { ilmiah }\end{array}$ & $\begin{array}{l}\text { Pemilihan judul } \\
\text { ensiklopedia } \\
\text { tepat }\end{array}$ & 100 & 80 & 90 & $\begin{array}{l}\text { Sangat } \\
\text { Valid }\end{array}$ \\
\hline 4 & $\begin{array}{l}\text { Menambah } \\
\text { rasa ingin } \\
\text { tahu }\end{array}$ & $\begin{array}{l}\text { Penempatan } \\
\text { gambar latar } \\
\text { belakang tidak } \\
\text { mengganggu } \\
\text { judul, teks, } \\
\text { angka dan } \\
\text { halaman pada } \\
\text { ensiklopedia }\end{array}$ & 100 & 100 & 100 & $\begin{array}{c}\text { Sangat } \\
\text { Valid }\end{array}$ \\
\hline 5 & $\begin{array}{l}\text { Sistematika } \\
\text { materi } \\
\text { ensiklopedia }\end{array}$ & $\begin{array}{l}\text { Gambar dan } \\
\text { keterangan } \\
\text { gambar jelas }\end{array}$ & 100 & 100 & 100 & $\begin{array}{c}\text { Sangat } \\
\text { Valid }\end{array}$ \\
\hline 6 & $\begin{array}{l}\text { Pemahaman } \\
\text { terhadap isi } \\
\text { ensiklopedia }\end{array}$ & $\begin{array}{l}\text { Kesesuaian } \\
\text { gambar dengan } \\
\text { materi } \\
\text { ensiklopedia }\end{array}$ & 100 & 100 & 100 & $\begin{array}{c}\text { Sangat } \\
\text { Valid }\end{array}$ \\
\hline 7 & $\begin{array}{l}\text { Penjelasan } \\
\text { tentang } \\
\text { istilah yang } \\
\text { sulit } \\
\text { dipahami } \\
\text { (glosarium) }\end{array}$ & $\begin{array}{l}\text { Ukuran dan } \\
\text { warna huruf } \\
\text { sesuai }\end{array}$ & 100 & 80 & 90 & $\begin{array}{c}\text { Sangat } \\
\text { Valid }\end{array}$ \\
\hline \multicolumn{5}{|c|}{ Rata-rata } & 94,28 & \\
\hline
\end{tabular}

\section{PEMBAHASAN}

\section{Faktor Lingkungan}

Faktor lingkungan merupakan salah satu faktor yang sangat mempengaruhi kehidupan organisme, baik eksistensi maupun sistem metabolismenya. Jika salah satu faktor ini terganggu maka kehidupan echinodermata pun akan terganggu. Secara umum fauna echinodermata mampu bertahan hidup pada perairan dengan suhu 
berkisar antara $28-30^{\circ} \mathrm{C}$, kadar keasamaan antara 7,10 - 7,50, kadar salinitas kisaran 31,00 - 33,00\% (Rumahlatu dkk, 2008).

Berdasarkan pengukuran yang telah dilakukan dapat diketahui bahwa temperatur air Pantai tanjung Setia yaitu berkisar $27^{\circ}-29^{\circ} \mathrm{C}, \mathrm{pH}$ $7,2-7,6,20-26 \%$ dan DO 19-23. Dengan demikian faktor lingkungan Pantai Tanjung Setia dapat dikatakan layak sebagai tempat hidup fauna echinodermata.

\section{Keanekaragaman Echinodermata}

Berdasarkan penelitian yang telah dilakukan diperoleh bahwa jumlah spesies echinodermata yang diperoleh yaitu sebanyak 12 spesies dari 4 kelas.

\begin{tabular}{|c|c|c|c|c|c|}
\hline \multirow{2}{*}{ No } & \multirow{2}{*}{ Nama spesies } & \multicolumn{3}{|c|}{ Stasiun } & \multirow{2}{*}{$\Sigma$} \\
\hline & & 1 & 2 & 3 & \\
\hline $\mathbf{I}$ & \multicolumn{5}{|l|}{ Aste roidea } \\
\hline 1 & $\begin{array}{l}\text { Echinaster } \\
\text { luzonicus }\end{array}$ & + & + & + & 6 \\
\hline 2 & $\begin{array}{l}\text { Linckia } \\
\text { laevigata }\end{array}$ & + & + & + & 69 \\
\hline II & \multicolumn{5}{|l|}{ Ophiu roi dea } \\
\hline 3 & $\begin{array}{l}\text { Ophicoma } \\
\text { scolopendrina }\end{array}$ & + & + & - & 795 \\
\hline III & \multicolumn{5}{|l|}{ Echinoidea } \\
\hline 4 & $\begin{array}{l}\text { Diadema } \\
\text { antillanum }\end{array}$ & + & + & + & 126 \\
\hline 5 & $\begin{array}{l}\text { Echinothrix } \\
\text { calamaris }\end{array}$ & + & + & + & 179 \\
\hline 6 & $\begin{array}{l}\text { Tripneustes } \\
\text { ventricosus }\end{array}$ & + & + & + & 83 \\
\hline IV & \multicolumn{5}{|l|}{ Holonthu roidea } \\
\hline 7 & $\begin{array}{l}\text { Holonthuria } \\
\text { atra }\end{array}$ & + & + & + & 110 \\
\hline 8 & $\begin{array}{l}\text { Holonthuria } \\
\text { impatiens }\end{array}$ & + & + & + & 105 \\
\hline 9 & $\begin{array}{l}\text { Holonthuria } \\
\text { leucospilota }\end{array}$ & + & + & + & 48 \\
\hline 10 & $\begin{array}{l}\text { Stichopus } \\
\text { monotuberculat } \\
\text { us }\end{array}$ & + & + & + & 102 \\
\hline 11 & $\begin{array}{l}\text { Molpadia } \\
\text { oolitica }\end{array}$ & + & - & - & 35 \\
\hline 12 & $\begin{array}{l}\text { Synapta } \\
\text { maculata }\end{array}$ & + & + & + & 96 \\
\hline
\end{tabular}

Spesies yang paling banyak ditemukan yaitu Ophiocoma scholopendrina dengan jumlah 795 dan spesies yang paling sedikit yaitu
Molpadia oolitica dengan jumlah 35 ekor.

\section{a. Indeks Keanekaragaman \\ Echinodermata}

Indeks keanekaragaman digunakan untuk mengetahui tingkat keanekaragaman echinodermata di Pantai Tanjung Setia. Berdasarkan data yang telah diperoleh, diketahui bahwa indeks keanekaragaman ( $\left.\mathrm{H}^{\prime}\right)$ echinodermata di stasiun 1 yaitu sebesar 1,8031, stasiun 2 sebesar 2,0351, dan stasiun 3 yaitu sebesar 2,1794. Apabila dirata-ratakan maka nilai $H^{\prime}$ dari ketiga stasiun akan diperoleh 2,006. Menurut ShannonWinner nilai $\mathrm{H}^{\prime} 1<\mathrm{H}<3$ : keanekaragaman sedang, berdasarkan kriteria ShannonWienner tersebut, nilai indeks keanekaragaman (H') echinodermata pantai Tanjung Setia adalah sedang. Hal ini disebabkan karena adanya perbedaan komposisi, jenis dan jumlah individu, sehingga mempengaruhi nilai keanekaragaman jenis masing-masing tiap pertumbuhan. Suatu komunitas dapat dikatakan memiliki indeks keanekaragaman tinggi apabila pada komunitas tersebut tersusun atas banyak spesies dengan kelimpahan spesies yang sama atau hampir sama.

\section{b. Indeks Dominansi \\ Echinodermata}

Indeks dominansi digunakan untuk mengetahui spesies echinodermata tertentu yang mendominasi disuatu habitat. Berdasarkan hasil perhitungan, nilai tertinggi dari ketiga stasiun adalah stasiun 1 yaitu sebesar 0,28 dan terendah adalah stasiun 3 yaitu 0,12 . Nilai indeks dominansi stasiun 1 lebih besar dari stasiun-stasiun lain dikarenakan pada stasiun 1 terdapat satu spesies yang mendominasi yaitu 
bintang ular (Ophiocoma scholopendrina) dengan jumlah 782 ekor.

Secara umum nilai indeks dominansi (ID) echinodermata pantai tanjung Setia Kabupaten Pesisir Barat yaitu sebesar 0,1925. Nilai tersebut berada pada kategori rendah. Apabila nilai indeks dominansi berada pada rentang $0-0,50$, dapat dikatakan bahwa indeks dominansi rendah. Nilai indeks yang rendah dapat pula diartikan bahwa ada beberapa spesies yang mendominasi pantai Tanjung Setia Kabupaten Pesisir Barat (Ardhana: 2012).

\section{Pemanfaatan Hasil Penelitian sebagai Sumber Belajar}

Kegiatan belajar mengajar yang nantinya akan diharapkan mampu merubah seseorang dari keadaa. Hasil inventarisasi echinodermata di Pantai Tanjung Setia dibuat menjadi sebuah sumber belajar berupa buku ensiklopedia. Ensiklopedia dengan judul "Echinodermata Pantai Tanjung Setia" ini telah melalui tahap validasi oleh dua orang ahli. Aspek yang dinilai oleh masing-masing ahli yaitu materi ensiklopedia dan desain ensiklopedia.

Berdasarkan perhitungan yang telah dilakukan dapat diketahui bahwa nilai yang diperoleh dari kedua ahli adalah 94, 28\% dan berada pada kategori sangat valid. Dengan kata lain ensiklopedia yang dibuat dari hasil inventarisasi echinodermata di pantai Tanjung Setia, dikatakan layak untuk digunkan sebagai sumber belajar oleh peserta didik.

\section{KESIMPULAN}

Berdasarkan hasil penelitian yang telah diungkap dalam hasil dan pembahasan maka dapat disimpulkan bahwa:

1. Spesies echinodermata yang ditemukan di Pantai Tanjung Setia Kabupaten Pesisir Barat meliputi kelas Asteroidea (Linckia laevigata dan Echinaster luzonicus), kelas Ophiuroidea (Ophiocoma scholopendrina), kelas Echinoidea (Diadema antillarum, Echinothrix calamaris, dan Tripneustes ventricosus), dan kelas Holonthuroidea (Holonthuria atra, Holonthuria leucospilota, Holonthuria impatiens, Synapta maculata, Stichopus monotuberculatus, Molpadia oolitica)

2. Indeks keanekaragaman (H') echinodermata di Pantai Tanjung Setia Kabupaten Pesisir Barat sebesar 2,006 yaitu dalam kategori sedang. Indeks dominansi (ID) echinodermata pantai Tanjung Setia Kabupaten Pesisir Barat sebesar 0,1925 yaitu dalam kategori rendah, dominansi terpusat pada beberapa spesies.

3. Ensiklopedia yang telah dikembangkan memiliki persentase nilai 94, 28 yang berarti ensiklopedia yang dikembangkan layak untuk digunakan oleh peserta didik.

\section{DAFTAR RUJUKAN}

Ardhana, I. P. G. 2012. Ekologi Tumbuhan. Bali: Udayana University Press.

Apriliani, A., G. Gunatama dan M. S. Indriani. 2014. Hubungan Kelimpahan Fitoporifiton dengan Konsentrasi Nitrat dan Ortofosfat pada Daun Enhalus acoroides di Perairan 
Pantai Jepara. Diponegoro Journal Of Maquares volume 3, nomor 3, tahun 2014, hal 18-27. Universitas Diponegoro

Arikunto, S. 2010. Prosedur Penelitian Suatu Pendekatan Praktek. Yogyakarta: Rineke Cipta.

Devy, R. 2015. Pengembangan Ensiklopedia Brainware of Chemistry Tokoh Kimia di Buku Kelas X SMA/MA Sebagai Sumber Pengetahuan dan Pendidikan Karakter Bagi Siswa. Disertasi tidak diterbitkan. Yogyakarta: Universitas negeri Yogyakarta

Pallo, N.C., dan N. Lewaherilla. 2001. Jenis-jenis teripang (Holonthuroidea) di Perairan Kampung Auki Distrik Padaido Kabupaten Biak Numfor Papua. Jurnal Biologi papua volume 3 no. 1 . Universitas Cendrawasih

Rappe, A.R. 2010. Struktur Komunitas Ikan pada Padang Lamun yang Berbeda di
Pulau Barrang Lompo. Jurnal ilmu dan teknologi kelautan tropis, vol. 2, no. 2, desember 2010. Makasar: Hasanuddin University.

Romimohtarto, K., dan S. Juwana. 2007. Biologi Laut. Jakarta: Djambatan.

Rumahlatu, D., A. Gofur dan H. Sutomo. 2008. Hubungan Faktor Fisika-Kimia Lingkungan Dengan Keanekaragaman

Echinodermata Pada Daerah Pasang Surut Pantai Kairatu. MIPA, Januari tahun 2008 halaman 77-85. F. MIPA Universitas Negeri Malang

Sianipar, M. S., L. Djaya, E. Santosa, R.C.H. Soesilohadi, W.D. Natawigena dan M. P. Bangun. 2015. Indeks Keragaman Serangga Hama Pada Tanaman Padi di Lahan Persawahan Padi Dataran Tinggi Desa Sukawening Kecamatan Ciwidey Kabupaten Bandung. Bioma Juni 2015 vol. 17, no. 1. UNPAD 